\title{
Synthesis of (+/-)-Curcumene Ether
}

\author{
Troy D. Vickers, Brian A. Keay*
}

Department of Chemistry, University of Calgary, Calgary, Alberta, T2N IN4, Canada

Fax +1(403)2841372; E-mail: keay@ ucalgary.ca

Received 20 November 2003

\begin{abstract}
A 9 step synthesis of (+1-)-curcumene ether is described starting from 5-bromo-2-methyl-2-pentene and 2-amino-5-methylphenol in $7 \%$ overall yield using an intramolecular Heck reaction as the key transformation to generate a stereogenic quaternary center.
\end{abstract}

Key words: total synthesis, intramolecular Heck reaction, spiro compounds, lactones, natural products

Our interest in the asymmetric intramolecular Heck reaction as a key step for the synthesis of natural products ${ }^{1}$ has resulted in our expanding the application of this reaction towards the synthesis of pyran containing natural products $^{2}$ whereby a stereogenic center is created at the C2 position of the pyran ring. To our knowledge, the intramolecular Heck strategy. ${ }^{3}$ has not been used to generate pyran rings containing an aryl group as one of the substituents on the stereogenic center at C-2. This paper describes the synthesis of $(+/-)$-curcumene ether $(1)$ in which the stereogenic center is created via an intramolecular Heck reaction.

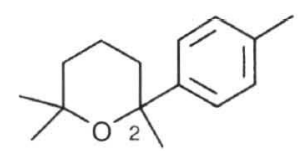

1 (+/-)-curcumene ether<smiles>Cc1ccc(OC(=O)C2=CCCC(C)(C)O2)c(I)c1</smiles><smiles>C=CCC1=C(C(=O)O)CCC(C)(C)O1</smiles>

5

Scheme 1
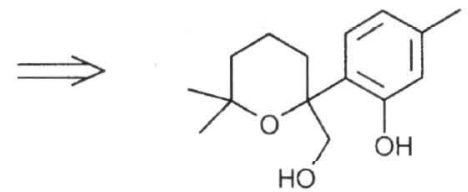

2

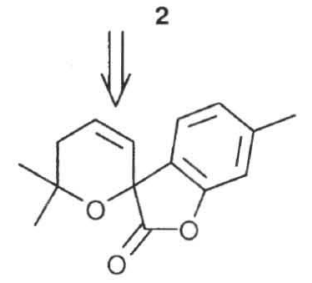

3
The sesquiterpene curcumene ether (1) was isolated from the plant Thuja orientalis in $1969 .{ }^{4}$ To date there have been three syntheses of $(+/-)-1$ reported in the literature. The first of these was reported by Vig and coworkers ${ }^{5}$ in 1973 but their synthesis could not be repeated by Paknikar and coworkers in $1980 .{ }^{6}$ Consequently, there are only two valid syntheses of $(+/-)-1$. The first by Mashrequi and Trivedi $^{7}$ in 1978 and the second by Kametani et al in $1984 .{ }^{8}$ Only recently has the first stereoselective synthesis of $(R)-(+)-1$ been reported by Serra. ${ }^{9}$ This synthesis involved a resolution of cinenic acid and provided $(R)-(+)-$ 1 in 13 steps with an overall yield of $3 \%$.

The retrosynthesis towards curcumene ether (1) is illustrated in Scheme 1. Retrooxygenation of $\mathbf{1}$ at the C-2 methyl group and ortho-position of the aromatic ring provides 2 . Retrooxidation of the hydroxymethyl group and ring closure to a lactone gives 3 that should be formed via an intramolecular Heck reaction with ester 4. Disconnection of ester 4 gives acid 5 and iodophenol 6. Compounds 5 and 6 are easily prepared as outlined in Scheme 2.

2-Iodo-5-methylphenol (6) was prepared by diazotization of 2-amino-5-methylphenol (7) ${ }^{10}$ with isoamyl nitrite and $\mathrm{HBF}_{4}$ in ether to give the stable diazonium tetrafluoroborate intermediate 8 in $86 \%$ yield. ${ }^{11}$ Treatment of 8 with $\mathrm{NaI}$ in refluxing acetone afforded the 2-iodo-5-methylphenol (6) ${ }^{12}$ in $71 \%$ yield.

The synthesis of pyran acid $\mathbf{5}$ started with 5-bromo-2-methyl-2-pentene (9). ${ }^{13}$ Bromide 9 was converted to iodide 10 using $\mathrm{NaI}$ in acetone. Halogen-metal exchange of iodide 10 with $t$-BuLi (ether, $-78^{\circ} \mathrm{C}$ ) provided an alkyllithium species that was added slowly to $\mathrm{a}-78^{\circ} \mathrm{C}$ solution of 10 equiv of diethyl oxalate in ether. Standard workup provided ketoester 11 in $52 \%$ yield from bromide 9 . Hydrolysis of ester 11 to an acid followed by purification by distillation unexpectedly gave pyran acid 5 in $65 \%$ yield. Previous syntheses of $\mathbf{5}$ from the corresponding acid of $11^{13}$ required heating the acid with formic acid for $15 \mathrm{~min}$ utes. In our hands, the heat applied during the distillation must resulted in the acid auto catalyzing itself to form pyran 5 in the distillation bulb. DCC coupling of acid 5 and phenol 6 in $\mathrm{CH}_{2} \mathrm{Cl}_{2}$ with DMAP gave 4 in $88 \%$ yield. With ester 4 in hand, the intramolecular Heck cyclization was attempted. Treatment of a mixture of pentamethylpiperidine and 4 in $N, N$-dimethylacetamide (DMA) with a mixture of $\operatorname{Pd}_{2}(\mathrm{dba})_{3}$ and (+/-)-BINAP (in DMA) followed by refluxing the solution for $4 \mathrm{~d}$ provided a $1: 1$ mixture of double bond isomers 12 and $13 .{ }^{14-16}$ Changing the source of $\mathrm{Pd}$, base and/or solvent resulted in complex 


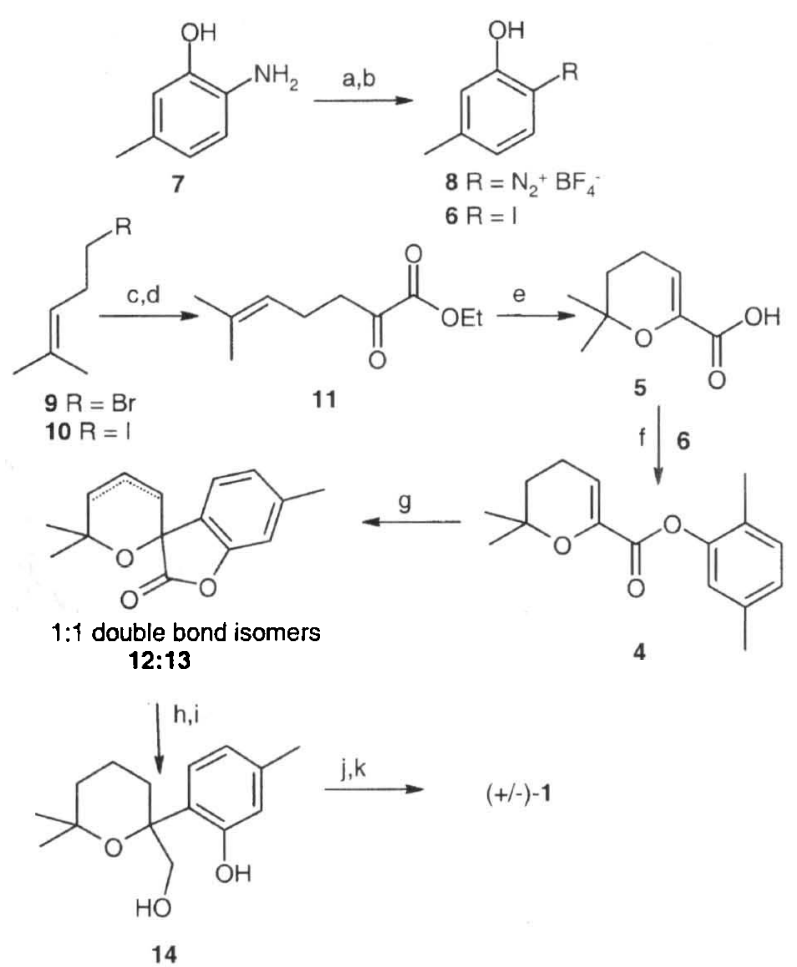

Scheme 2 Reagents and conditions: a) $\mathrm{HBF}_{4}, \mathrm{Et}_{2} \mathrm{O}$, isoamyl nitrite, $\mathrm{EtOH}, 0^{\circ} \mathrm{C}, 30 \mathrm{~min}(86 \%)$; b) NaI, acetone, reflux, $3 \mathrm{~d}(7 \mathrm{I} \%)$; c) NaI, acetone, r.t., $20 \mathrm{~h}(92 \%)$; d) 2 equiv. $t$-BuLi, $\mathrm{Et}_{2} \mathrm{O},-78{ }^{\circ} \mathrm{C}, 1 \mathrm{~h}$; then 10 equiv diethyl oxalate, $\mathrm{Et}_{2} \mathrm{O},-78{ }^{\circ} \mathrm{C} .4 \mathrm{~h}(52 \% 2$ steps): e) $\mathrm{KOH}$, $\mathrm{H}_{2} \mathrm{O}$, EtOH, reflux, $20 \mathrm{~h}: 1 \% \mathrm{HCl}$, purification at $100{ }^{\circ} \mathrm{C}, 0.4 \mathrm{mmHg}$ (64\%); f) 6, DCC, DMAP, $\mathrm{CH}_{2} \mathrm{Cl}_{2}$, r.t., $20 \mathrm{~h}(88 \%)$ : g) $\mathrm{Pd}_{2}$ (dba) ${ }_{3}$. (+/-)-BINAP, $N, N$-dimethylacetamide, $N_{2}$, r.t., $45 \mathrm{~min}$; then add to 4 . pentamethylpiperidine, $N, N$-dimethylacetamide, argon, $100{ }^{\circ} \mathrm{C}, 4 \mathrm{~d}$ (90\%); h) $\mathrm{LiAlH}_{4}$, Et 2 O, r.t., 20 h: i) 1 atm $\mathrm{H}_{2}, 5 \% \mathrm{Pd} / \mathrm{C}$, EtOH, r.t., $20 \mathrm{~h}(86 \%, 2$ steps $)$; j) 2.2 equiv $\mathrm{NaH}$, THF, then add diethylchlorophosphate, r.t., $2 \mathrm{~h} ; \mathrm{k}) \mathrm{Li}_{(\mathrm{s})}, \mathrm{NH}_{3(1)}, \mathrm{Et}_{2} \mathrm{O},-78^{\circ} \mathrm{C}, 30 \mathrm{~min}(57 \%, 2$ steps).

mixtures wherein unreacted SM, 12,13 and deiodizied 4 were obtained in varying ratios. Changing the time and temperature of the reaction did not noticeably change the ratio of $12: 13$. This was not a worry as the double bond was not necessary for the synthesis of curcumene ether. Reduction of the mixture of lactones 12 and 13 with $\mathrm{LiAlH}_{4}$ followed by a catalytic hydrogenation of a mixture of the isomeric olefins gave saturated diol 14 in $86 \%$ yield. The last step of the synthesis involved removal of both the hydroxyl and phenol groups simultaneously. This was accomplished by converting diol $\mathbf{1 4}$ into a bis(diethylphosphonate) ${ }^{17}$ followed by removal of both phosphonates by treatment with lithium metal in liquid ammonia to give (+/-)-curcumene ether (1) in 57\% yield from 14 .

In conclusion, we have developed a 9-step synthesis of (+/-)-curcumene ether (1) from 5-bromo-2-methyl-2-pentene (9) and 2-amino-5-methylphenol (7) in an overall yield of $7 \%$. We are currently preparing 2-trifluoromethanesulfonyloxy-5-methylphenol in order to attempt the intramolecular Heck reaction under asymmetric conditions. ${ }^{15}$ Applications of this strategy towards the synthesis of other 2-arylpyrans are currently underway.

\section{Acknowledgment}

We thank the Natural Science and Engineering Research Council of Canada and the University of Calgary for financial support.

\section{References}

(1) (a) Maddaford, S. P.; Andersen, N. G.: Cristofoli, W. A.; Keay, B. A. J. Am. Chem. Soc. 1996, 118, 10766. (b) Lau, S. Y. W.; Keay, B. A. Org. Lett. 2001, 3, 181. (c) Lau, S. Y. W.; Keay, B. A. Synlett 1999, 605, (d) Keay, B. A.: Maddaford, S. P.; Cristofoli, W. A.; Andersen, N. G.: Passafaro, M. S.; Wilson, N. S.; Nieman, J. A. Can. J. Chem. 1996, 75, 1163. (e) Cristofoli, W. A.: Keay, B. A. Synlett 1994. 625 .

(2) Woo, S.: Keay, B. A. Synlett 1996, 135.

(3) (a) Poli, G.; Giambastiani, G.; Heumann, A. Tetrahedron 2000, 56, 5959. (b) Ikeda, M.; ElBialy, S. A. A.; Yakura. T. Heterocycles 1999, 51, 1957. (c) Link, J. T.; Overman, L. E. In Metal-Catalyzed Cross-Coupling Reactions: Diederich, F.: Stang, P. J., Eds.: Wiley-VCH, Inc.: New York NY, 1998, 231. (d) Shibasaki, M.; Boden, C. D. J.: Kojima, A. Tetrahedron 1997, 53, 7371. (e) Gibson. S. E.: Middleton, R. J. Contemp. Org. Swnth. 1996, 3, 447.

(4) (a) Tomida, B.; Hirose, Y.; Nakatsuka, T. Mokuzai Gakkaishi 1969, 15, 47. (b) Tomida, B.; Hirose, Y. Mokuzai Gakkaishi 1969, 15, 337.

(5) Vig. O. P.: Kumar, H.; Salota, J. P.; Sharma, S. D. Indian J. Chem. 1973, 11,86 .

(6) Paknikar, S. K.: Dinge, A. S. Indian J. Chem. 1980, 19, 80.

(7) Mashrequi, S. H.: Trivedi, G. K. Indian J. Chem. 1978, 16. 849 .

(8) Kametani, T.; Kawamura, K.: Tsubuki, M.; Honda, T. J. Chem. Soc., Perkin Trans. 1 1984, 1305.

(9) Serra. S. Sinlett 2000, 890.

(10) Purchased from the Aldrich Chemical Company.

(11) (a) Sawaguchi, M.; Fukuhara. T.: Yoneda, N. J. Fluor. Chem. 1999, 97, 127. (b) Yoneda, N.; Fukuhara, T.: Mizokami, T.; Suzuki, A. Chem. Lett. 1991, 459.

(12) Cambie, R. C.: Rutledge, P. S.; Smith-Palmer, T.; Woodgate, P. D. J. Chem. Soc., Perkin Trans. 1 1976, 1161

(13) Hiranuma. S.: Shibata. M.; Hudlicky, T.J. Org. Chem. 1983, 48,5321 .

(14) (a) Ashimori, A.; Bachand, B.; Overman, L. E.; Poon, D. J. J. Am. Chem. Soc. 1998, 120, 6477. (b) Ashimori. A.: Bachand, B.; Calter, M. A.; Govek, S. P.; Overman, L. E.; Poon, D. J. J. Am. Chem. Soc. 1998, 120, 6488.

(15) Experimental procedure for the conversion of 4 to 12 and 13: A mixture of $\mathrm{Pd}_{2}(\mathrm{dba})_{3}(13 \mathrm{mg}, 0.0141 \mathrm{mmol}),(+/-)$-BINAP (17.0 mg, $0.0273 \mathrm{mmol}$ ), and dry DMA $(2.5 \mathrm{~mL})$ under $\mathrm{N}_{2}$ was added after $45 \mathrm{~min}$. via syringe to a 2 dram screw-top vial containing ester 4 (52.3 mg, 0.14l mmol). PMP (127 $\mu \mathrm{L}, 0.705 \mathrm{mmol}$ )was added and the mixture was heated in the sealed vial at $100^{\circ} \mathrm{C}$ for 4 days. The solution was poured into ether and washed with saturated $\mathrm{NaHCO}_{3}$ aq $(4 \times 10$ $\mathrm{mL})$ and $\mathrm{NaCl}$ aq $(4 \times 10 \mathrm{~mL})$. The ether extracts were dried over anhydrous $\mathrm{MgSO}_{4}$, filtered and ether removed under reduced pressure to give a red/black residue. The oil was purified by flash chromatography (20:1, hexanes: EtOAc) to give a mixture $1: 1$ mixture of 12 and $13(31 \mathrm{mg}, 90 \%)$. IR $\left(\mathrm{cm}^{-1}\right) 1814$ (ester $\mathrm{C}=\mathrm{O}$ ), 1629 (alkene $\mathrm{C}=\mathrm{C}$ ): ${ }^{1} \mathrm{H}$ NMR $\delta$ 1.35 (br s, $3 \mathrm{H}, \mathrm{H}-1$ or H-2), 1.39 (br s, $3 \mathrm{H}, \mathrm{H}-10$ or $\mathrm{H}-11$ ), 1.43 (br s, $3 \mathrm{H}, \mathrm{H}-1$ or H-2). 1.49 (br s, $3 \mathrm{H}, \mathrm{H}-10$ or H-11), $2.31(\mathrm{~m}, 2 \mathrm{H}, \mathrm{H}-14), 2.38$ (br s, $6 \mathrm{H}, \mathrm{H}-8$ and H-17), $2.44(\mathrm{~m}$, $2 \mathrm{H}, \mathrm{H}-3), 5.63$ (dt, $1 \mathrm{H}, J=10.1 \mathrm{~Hz}, J=2.05 \mathrm{~Hz}, \mathrm{H}-12$ ), 5.89-6.08 (m, $2 \mathrm{H}, \mathrm{H}-4$ and $\mathrm{H}-5), 6.23(\mathrm{dt}, 1 \mathrm{H}, J=10.3 \mathrm{~Hz}$, $J=4.2 \mathrm{~Hz}, \mathrm{H}-13), 6.87-7.36(\mathrm{~m}, 6 \mathrm{H}, \mathrm{H}-6, \mathrm{H}-7, \mathrm{H}-9, \mathrm{H}-15$, 
$\mathrm{H}-16$, and $\mathrm{H}-18) ;{ }^{1.3} \mathrm{C}$ NMR $\delta 21.8\left(2 \times \mathrm{CH}_{3}\right), 28.6\left(\mathrm{CH}_{3}\right)$, $29.0\left(\mathrm{CH}_{3}\right) 29.9\left(\mathrm{CH}_{3}\right), 30.1\left(\mathrm{CH}_{3}\right), 30.8\left(\mathrm{CH}_{2}\right), 35.8\left(\mathrm{CH}_{2}\right)$, $72.9\left(\mathrm{C}_{\mathrm{q}}\right), 73.7\left(\mathrm{C}_{\mathrm{q}}\right), 74.9\left(\mathrm{C}_{\mathrm{q}}\right), 76.9\left(\mathrm{C}_{\mathrm{q}}\right), 111.6(\mathrm{CH}), 111.7$ $(\mathrm{CH}), 118.3(\mathrm{CH}), 124.0(\mathrm{CH}), 124.4(\mathrm{CH}), 124.7(\mathrm{CH})$, 125.0 (CH), $125.3(\mathrm{CH}), 126.6\left(\mathrm{C}_{q}\right), 127.0\left(\mathrm{C}_{q}\right), 127.4(\mathrm{CH})$, 135.6 (CH), $141.1\left(\mathrm{C}_{\mathrm{q}}\right), 141.2\left(\mathrm{C}_{4}\right) 153.1\left(\mathrm{C}_{\mathrm{q}}\right), 153.4\left(\mathrm{C}_{4}\right)$, $174.8\left(\mathrm{C}_{4}\right), 175.5\left(\mathrm{C}_{\mathrm{q}}\right)$; Mass spectra: (Compound 12) $244(1$, $\left.\mathrm{M}^{+}\right), 216\left(26, \mathrm{M}^{+}-\mathrm{CO}\right), 202(14), 201\left(100, \mathrm{M}^{+}-\mathrm{CO}\right.$ and $\left.-\mathrm{CH}_{3}\right), 187(4), 135$ (29), 134 (11), 67 (12); (Compound 13) $244\left(20, \mathrm{M}^{+}\right), 216\left(22, \mathrm{M}^{+}-\mathrm{CO}\right), 202(13), 201\left(100, \mathrm{M}^{+}-\mathrm{CO}\right.$ and $\left.-\mathrm{CH}_{3}\right), 161(50), 135(40), 115(14), 77(14)$; Mass calculated for $\mathrm{C}_{15} \mathrm{H}_{16} \mathrm{O}_{3}\left(\mathrm{M}^{+}\right): 244.10994$, found: 244.10954 .
(16) Attempts to perform the intramolecular Heck reaction on iodide 4 with enantiopure BINAP, BINAPFu, ${ }^{18}$ TetFuBINAP ${ }^{19}$ or Pfaltz's phosphinooxazoline ligand ${ }^{20}$ gave racemic mixtures of double bond isomers 12 and 13 .

(17) (a) Fuganti, C.; Serra, S. J. Org. Chem. 1999, 64, 8728. (b) Rossi, R. A.; Bunnett, J. F. J. Org. Chem. 1973, 38, 2314.

(18) Andersen, N. G.; Parvez, M.; Keay, B. A. Org. Lett. 2000, 2. 2817.

(19) Andersen, N. G.; McDonald, R.; Keay, B. A. Tetrahedron: Asymmetry 2001, 12, 263.

(20) Loiseleur, O.; Hayashi, M.; Schmees, N.; Pfaltz, A. Synthesis 1997, 1338. 